\title{
The Astronomy of the Megaliths of Chano
}

\author{
Subhashis Das \\ Individual Researcher, Hazaribagh, Jharkhand.Email: subdas.hzb@gmail.com
}

\begin{abstract}
Jharkhand is a fascinating land of megaliths, from the prehistoric to the contemporary times. Megaliths in the state of Jharkhand like that in the rest of the country have always been associated with the dead. The megalithic tribes in the state still erect a variety of megaliths on their deceased. That the positioning of several of these monuments was done by using astronomy and basic mathematics during the hoary times is not known to many. The megalithic site of Chano is an extraordinary creation of the ancients that stuns the one who surveys the monument's and each of its stones' placement as they reveal alignments toward cardinal points and the Solstical sunrises and sets. The positioning of the stones also displays the application of fundamental mathematics.
\end{abstract}

Keywords: Marang Buru, Mother Hills, Summer Solstice, Winter Solstice, sasandiri, hargarhi , cupules, Mother Goddess, Kesura, Bawanwey, Silwar Hill

\section{Introduction}

Megalithic burials of the tribals dated back to metal ages or earlier are the most enigmatic monuments. Fundamentally megaliths are burials and memorials of the dead. As result of latest researches megaliths have been found to be accessories of the once prevalent and the now defunct fertility cult. Megalithic burials being associated with spirit, ancestor and Goddess worship hence are also held as temple-burials (Das 2014). Scholars as Meaden and Hutton too have uphold their firm conviction that megaliths were also temples (Meaden 1992) (Hutton 1922). Cousens cites dolmens in South India which were shrines. He even writes about hundreds of dolmens having been erected in between Badami and Mahakuta by women pilgrims (Cousens 1926); hence these megaliths must have been revered by them. But not all megaliths are sepulchral as many of them are also assumed to be boundary markers and commemorative stones for various occasions. In the rural areas however many tribal and dalit communities perform ritualistic worship to these ancient stones and graves.

In 1956 Allchin authored a crucial paper in which he mentioned some forty non-sepulchral megaliths in the region of South Hyderabad including those of Nilurallu, Hanamsagar and Vibhuthihalli etc (Allchin 1956). He discovered that the stones inside the megalithic complex of Vibhutihalli were astronomically aligned towards the cardinal points and that they were also positioned in parallel lines and were spaced at regular intervals. He found that there were two different types of alignments which he later labelled as square and diagonal alignments. Paddaya subsequently discovered a few more non-sepulchral megaliths. Burjahom, Deosa and even Pakistan's Asota are few megaliths which were also found to be non-sepulchral.

Research by scientists of Tata Institute of Fundamental Research and Indian Institute of Astrophysics revealed astronomical links and orientations in Nilaskal, Vibhuthihalli and Nilurallu megaliths etc towards sunrises and sets of the Equinoxes and Solstices.

\footnotetext{
(c) AesthetixMS 2016. This Open Access article is published under a Creative Commons Attribution Non-Commercial 4.0 International License (http://creativecommons.org/licenses/by-nc/4.o/), which permits non-commercial re-use, distribution, and reproduction in any medium, provided the original work is properly cited. For citation use the DOI. For commercial re-use, please contact editor@rupkatha.com.
} 
Jharkhand is among the rarest places of the world where tribals as Mundas, Santals, Asurs, Hos and Oraons still build megaliths on their dead, as here megalith making is a continued tradition since unknown times (Das 2009). To the tribals in Jharkhand these megalithic burial sites are known with names as hargarhi, hargarha and jangarha et al. The megaliths, whose architecture differs from one tribe to other, are known to them as biridiri, burudiri and sasandiri etc (Das 2014). The prime burial custom in Jharkhand is that of in a pot or in a pitcher; however excavations and more study are required to arrive to a conclusive pronouncement.

\section{Hills are Essential to Position an Ancient Megalith}

Hills are sacred both for the tribals and the Hindus. To the present day tribal of Jharkhand, the hill corresponds to of their highly venerated Marang Buru. However, during hoary antiquity when the world was wrapped under the fertility cult, hills were revered both as the sacred breasts and as the sacred vulva considered to be representation of the ubiquitous Mother Goddess. The tradition of holding hills as pahadi or a female hill and pahad a male hill is yet maintained; a tradition that has origin in the fertility cult of hoary times. It is now known people in the ancient times regarded a certain shaped hill as the reclining pregnant Great Goddess; an auxiliary of the fecundity cult. Since megaliths were also accessories to the fertility cult, it became a prerequisite to align them to the Mother Hills in the horizon. The landscape housing the hills was maintained as the external boundary of the open-air megalithic temples (Cope 1998). Linking the hills to megalithic monuments by way of alignments therefore elevated them to the eminence of Goddess temples. If hills were held in such high esteem and revered as the representation of the Mother Goddess, the burials which were aligned to such hills exhibited the deceased's yearning to return to her womb for a better next life. Many bodies therefore inside megalithic graves have been found as within a Mother's womb (Cope 1998).

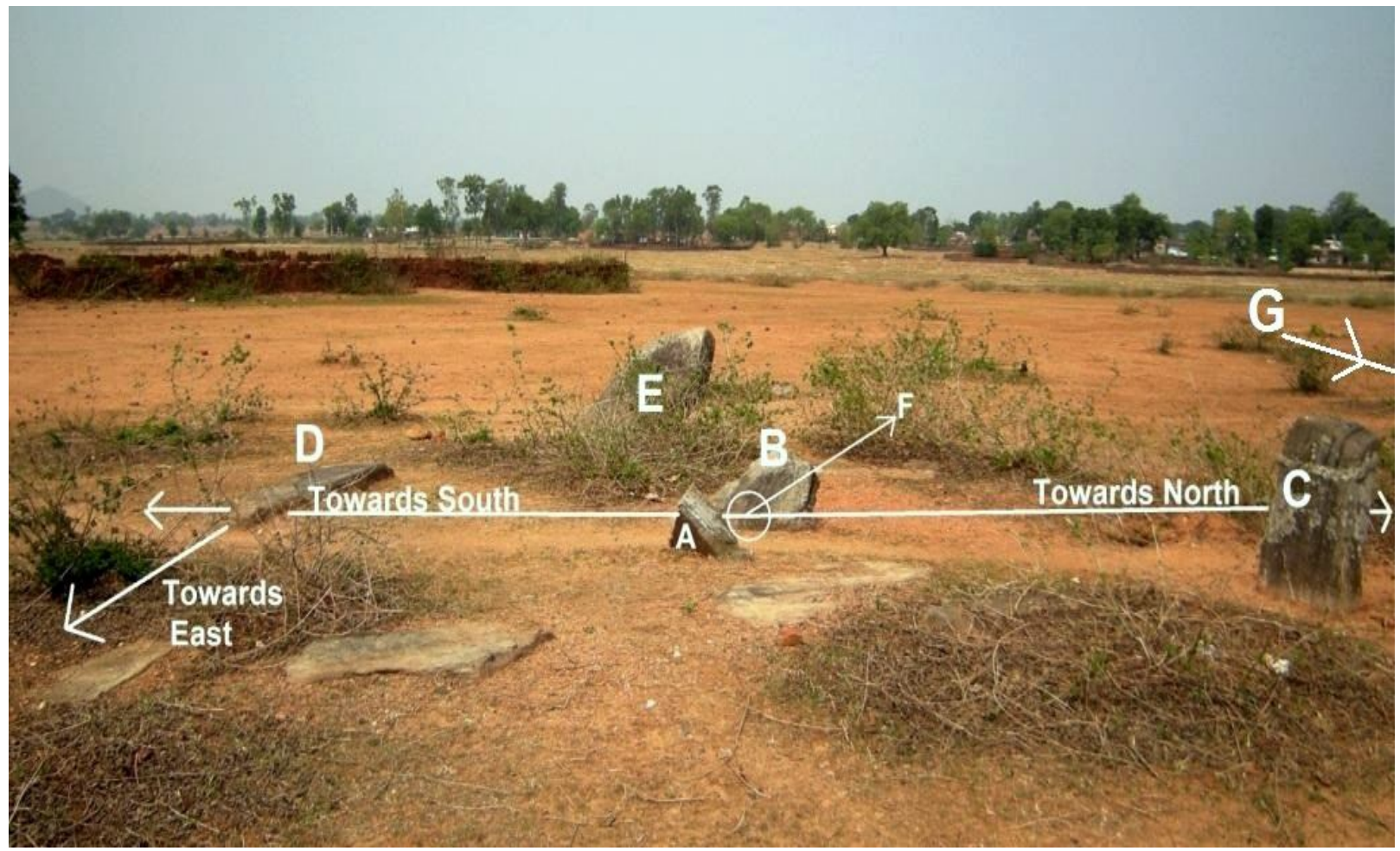

Plate 1. Megalithic complex of Chano 
Many a time, one finds that a few stones of an ancient megalithic complex are not aligned to any hill. In such cases, it is probable that they are oriented towards the cardinal points and the major sunrises or sets (Earls 2011).

The megaliths of Punkri Burwadih, Katia Murbey (Das 2010), Vibhuthihalli (Rao \& Thakur 2010), and Nilurallu (Rao, Thakur \& Mallinathpur 2011) etc reveal specific alignments towards cardinal points, major sunrises and sets or hills in the landscape. Much in the similar mode the Chano megaliths too demonstrate all the above mentioned alignments: towards cardinal points, the Kesura, Kanhari, Silwar and the Bawanwey Hills in the horizon and to the sunrises and sets of the Summer and Winter Solstices (Das 2014).

\section{The Megalith of Chano}

Situated about $6 \mathrm{kms}$ East of Hazaribagh Town in the state of Jharkhand, Chano is an ancient tribal hargarhi, housing randomly arranged five burial stones which the proto-austroloid Kolarian tribes of Jharkhand calls sasandiri. Due to its diminutive size, the site may appear very insignificant to the one who is unaware of the treasure this monument hides in itself $\left(\mathrm{Pl}_{1}\right)$.

For a better understanding of the megalithic complex, let us label the stones of the site in the following order:

1. The two triangles of comparative sizes: $\mathbf{A}$ and $\mathbf{B}$ respectively ( $\mathrm{Pl} 1$ \& Fig 1).The phallus: C (Pl 1, 3 \& Fig 1).

2. The East-West recumbent stone : D (Pl 1 \& 2 \& Fig 1)

3. The tall menhir : E ( $\mathrm{Pl}_{1} \&$ Fig 1$)$

4. The centre position between the gap of A \& B: F (Pl 1 \& Fig 1$)$

5. Imaginary spot to the North of the phallus on the North-South axis: G (Fig 1)

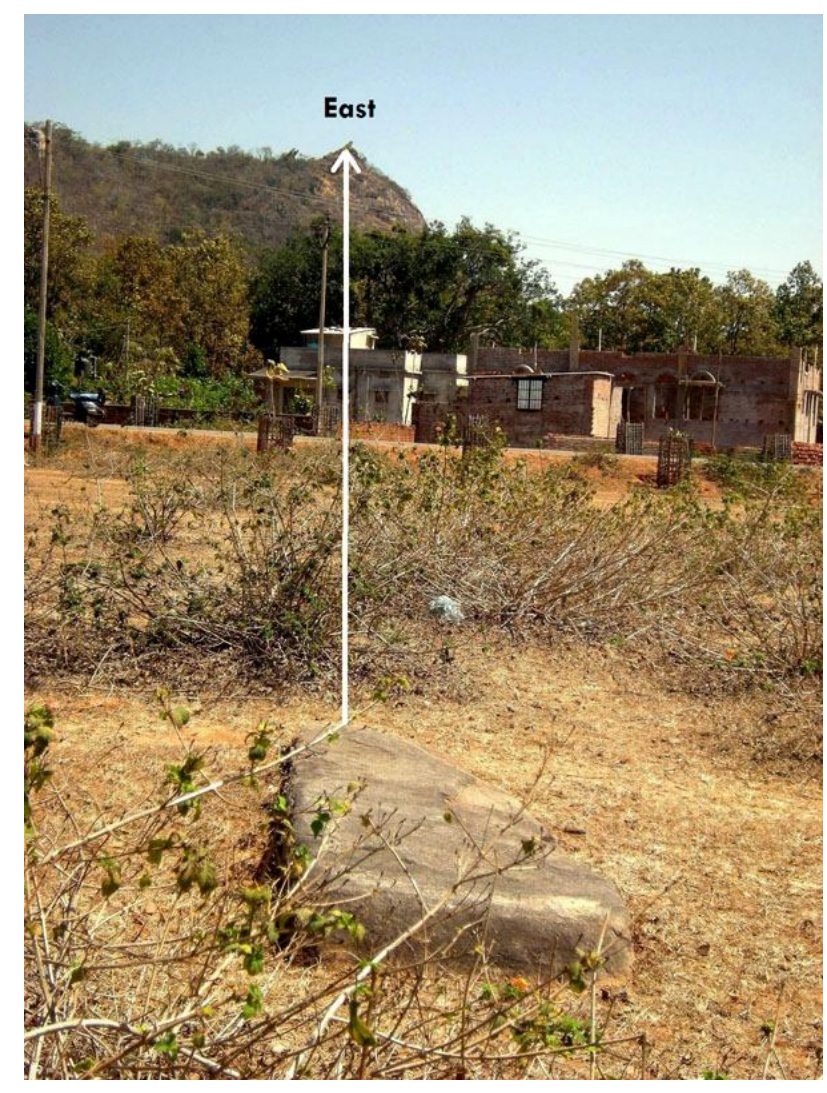

Plate 2. The recumbent stone $D$ with cupules is oriented towards east

A long and slim reclined stone D having a tentative length of $1.83 \mathrm{~m}$ is placed at an EastWest orientation ( $\mathrm{Pl}$ 2) with small cupules engraved on it in an east-west bearing. Cupules are circular indentations alleged to either be sepulchral relics or symbols of the all-pervading primitive Mother Goddess (Das 2009). Meaden believes them to be related to women (Meaden 1999). Under such a premise as only this east-west reclined stone bear cup marks; this stone was most likely intended to be a female stone. Female stones however are not unknown in megalithic cultures around the world. The Khasis in Meghalaya regard reclined stones to be female as they are laid in honour of "Ka-Yobai", the primeval omnipotent Mother Goddess (Chakravorty 93). Among the Angami Nagas, the recumbent stones on the ground are female principles and the erect stones represent the male, while for the Kachha Nagas, dolmens are female stones (Hutton 
1922). In Madagascar too the concept of the male and female stones among megaliths was once quite popular (Cope 1998).

The focus of this very ancient megalith is a $.74 \mathrm{~m}$ tall phallus with glans $\mathrm{C}$. Chano does not house the commonly seen tall menhirs or birdiri in many other megalithic sites in Jharkhand. This indeed raises questions, why is this so? There is however a tall stone in the site marked E which approximately is $1.68 \mathrm{~m}$ tall having a pointed tip resembling an arrow or a pointer. The stone exudes impressive hewing and polishing and is positioned at an incline of $52^{\circ}$.

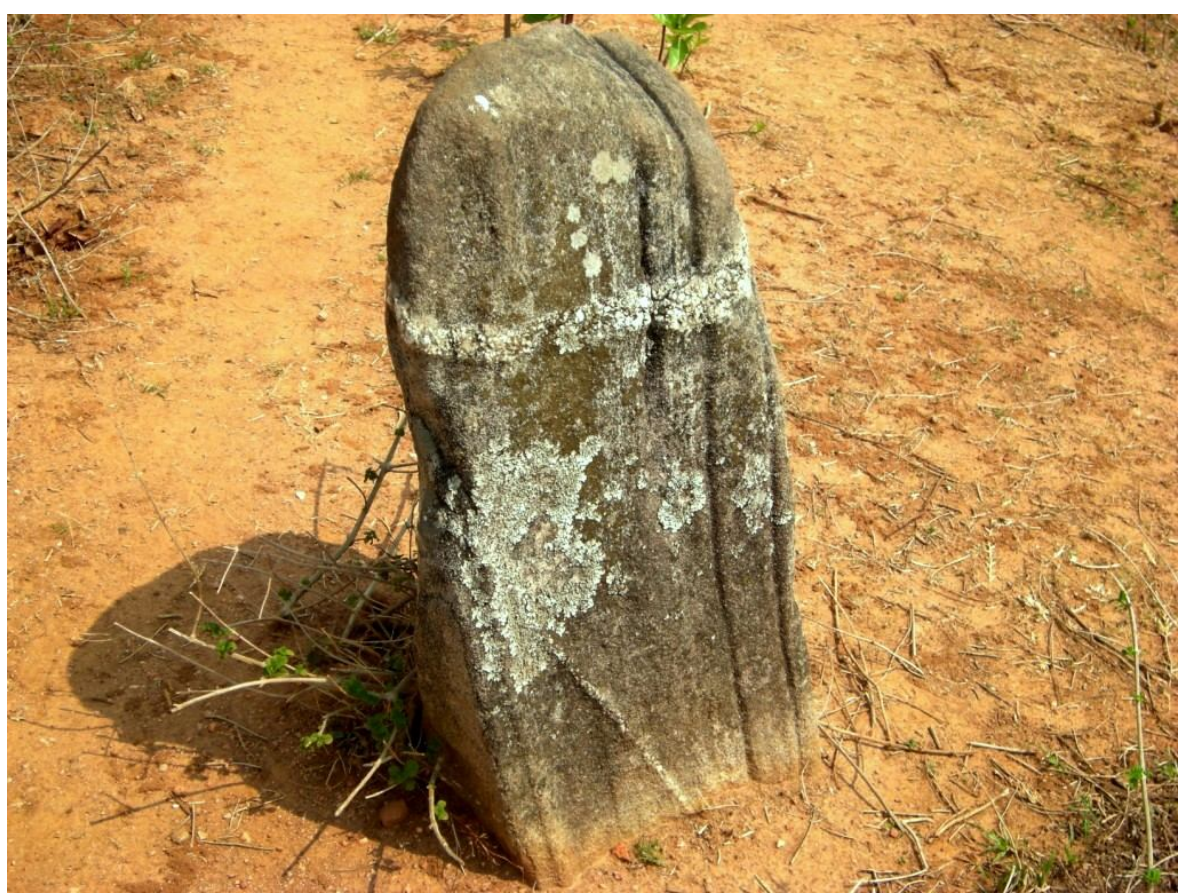

Plate 3. The phallus

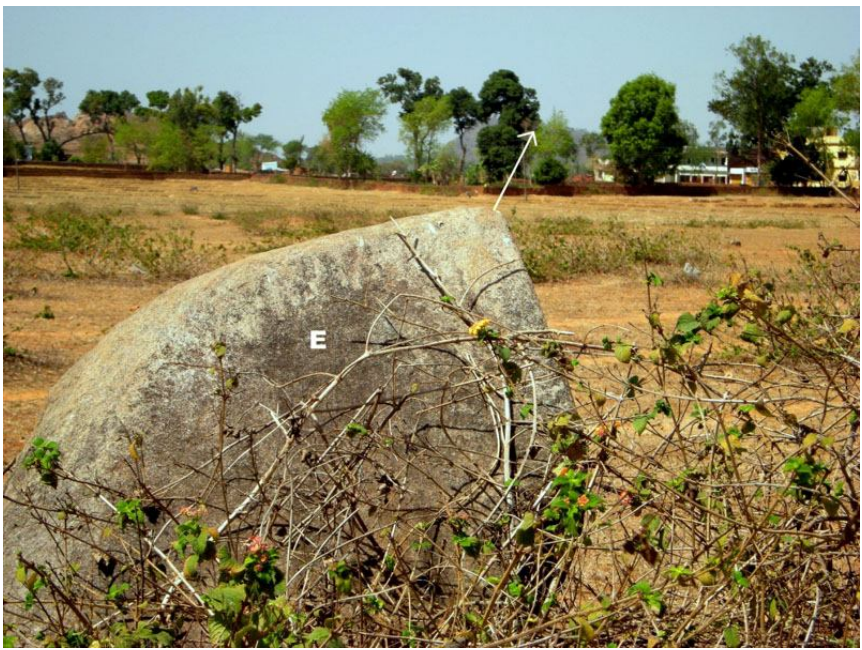

Plate 4. The largest pointer stone $E$ pints towards the Kanhari Hill in the landsacpe.

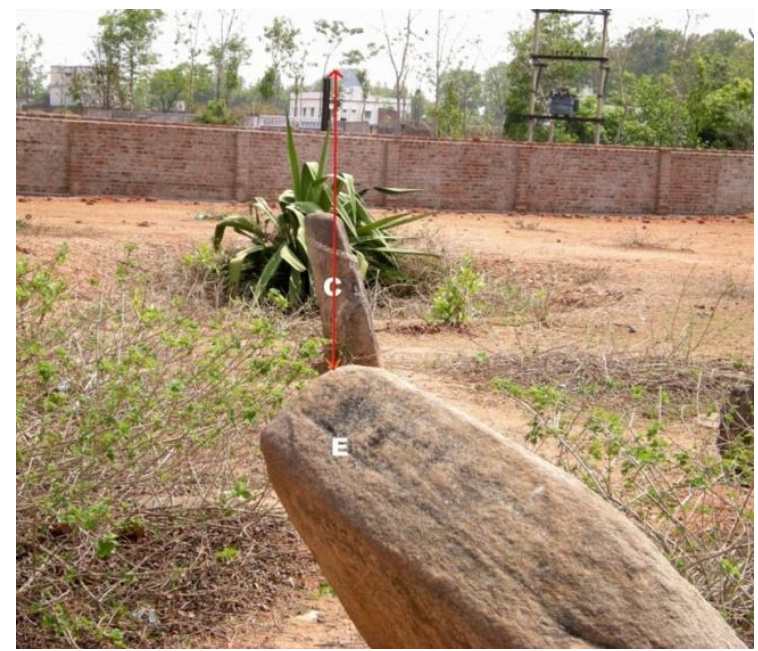

Plate 5. The largest pointer $E$ and the phallus $C$ is perfectly aligned to the conical Kesura Hill in the horizon. 
Two small comparative sized stone triangles A \& B with pointed vertexes are sited indicating the either sides. Stone triangles are a common feature in many megalithic sites of Hazaribagh (Das 2008); something not seen elsewhere. World over, triangles with their apexes to the top are believed to be phallic representation while the reverse symbolic of the female vulva (Cope 1998). In India triangles are tantric icons and much similar to the world outside triangles here too carry the same connotations. The presence of triangles in megalithic sites of Hazaribagh confirms to the possible practise of tantra type rites among the megalith makers of the region which may have been a precursor to Tantric Buddhism. However, triangles in megaliths as that in Chano can be seen to also have been used as pointers.

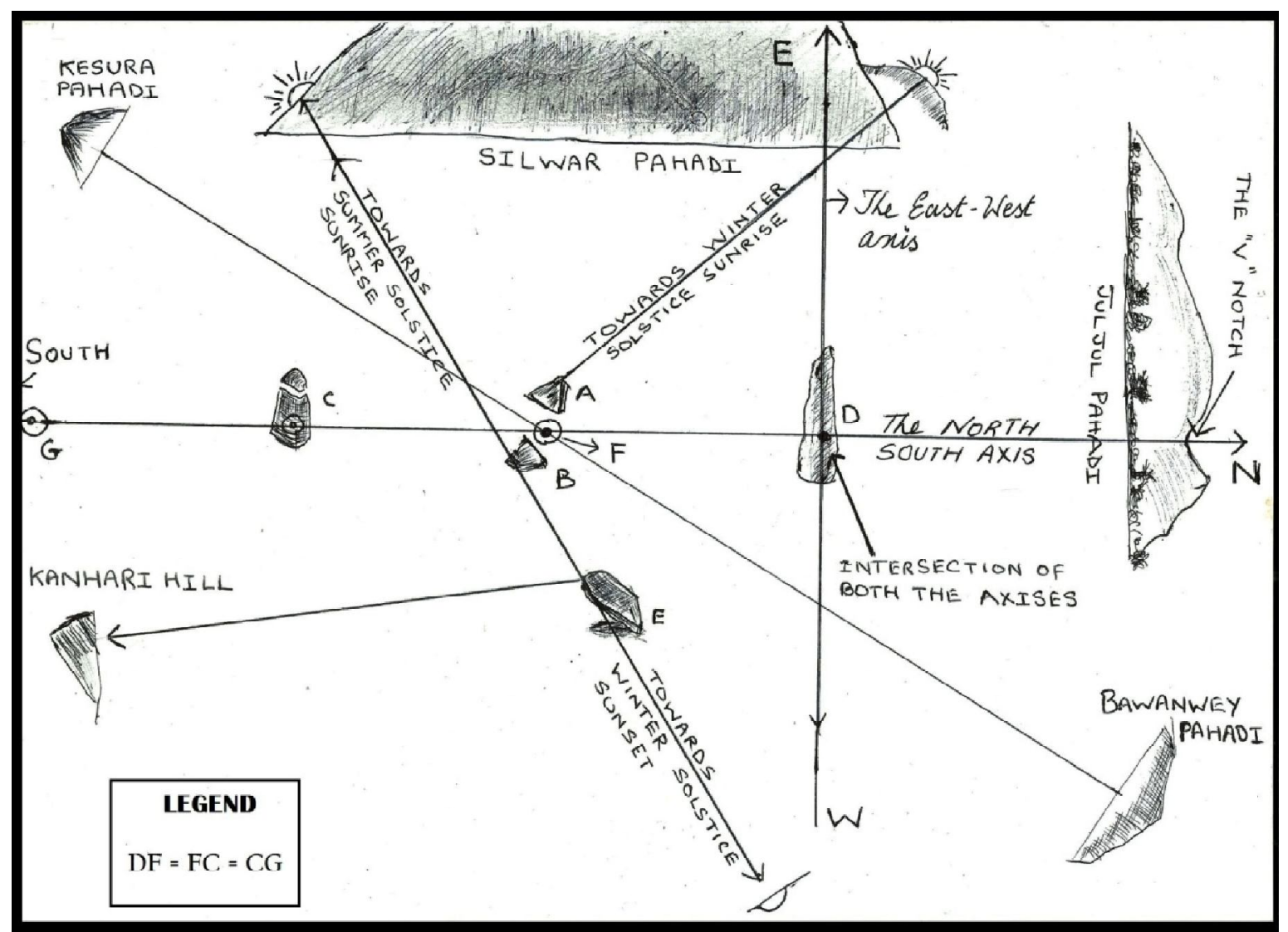

Fig 1. Lay out of the Chano megalithic site. Sketch showing the alignment towards the hills and the sunrises and sets of the Solstices.

\section{Alignments, Astronomy and Geometry}

As talked about in the above, hills were essential for the positioning of a megalith (Das 2009); Chano isn't an exemption either as the site too is aligned to hills in the landscape that encircle it. Why such alignments were mandatory for the positioning of megaliths is difficult to surmise. The ancient Indian text 'Surya Siddhanta' (Chakravarty 2001) does refer to alignments. The book mentions alignments of cities in the olden days as the madhyarekha or the axis of the earth which connects the merus or the poles that passes through Kurukhshetra, and the cities of Rohitak and Ujjyani. Kosambi believed that the sacred idols which the ancient 'savages' worshipped were usually placed at the intersection of roads (Kosambi 1962). 
Chano displays both understanding and knowledge of astronomy and geometry of the prehistoric megalith makers. Their knowledge of geometry as seen by its application in the site however is fundamental consisting of proportions and hex sectioning. On contrary to the later evolved Siddhnata astronomy of the Aryan scholars was based on calculations, the tribal astronomy of Chano was based on observation of the journey and the position of the sun, moon and the stars hence is better known as observational or horizon astronomy.

Standing at the centre of the shrine one can observe that the monument is located exactly "on" the unseen linear line between the Bawanwey and the Kesura Hills at $220^{\circ} \mathrm{SSW}$ and $40^{\circ} \mathrm{NNE}$ respectively (Fig 1). The tall megalith E having close resemblance to the pointer stones in the megalithic sites of Purni Mandar and Jabra, is inclined to $52^{\circ}$ towards the Kanhari Hill in the horizon at about $320^{\circ} \mathrm{NNW}(\mathrm{Pl} 4)$. Standing adjacent to E one can notice that this stone along with the phallus $C$ is located in perfect straight line to the conical Kesura hill in the NE horizon (Pl 5). The site is also oriented towards the Silwar Hill, a few hundred meters towards the Due East. As cited earlier, the cup marked recumbent female stone D rests in an east-west orientation. The stone that also is an assumed cover of a grave has its slender eastern tip serving as a cursor indicating towards the East at a cluster of stones atop the right flank of the Silwar Hill ( $\mathrm{Pl} 2$ ).

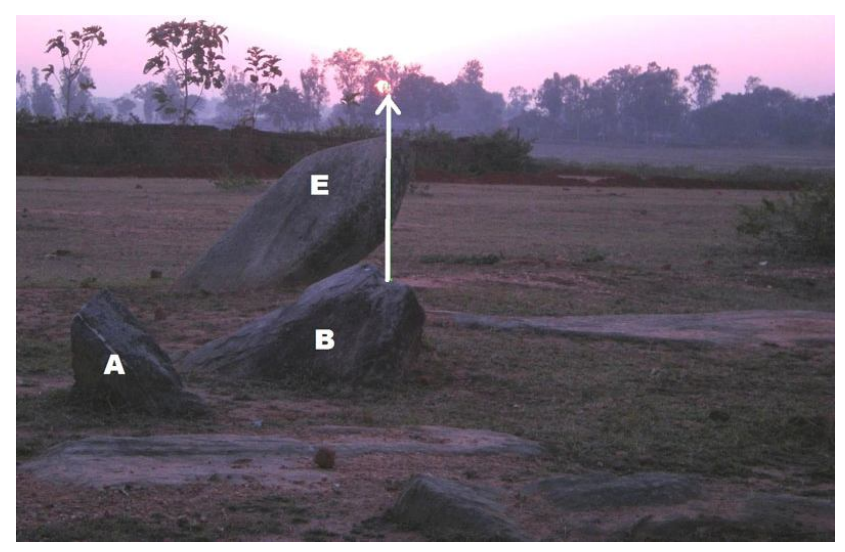

Plate 6. The two stones E \& B are positioned in straight line towards the Winter Solstice sunset.

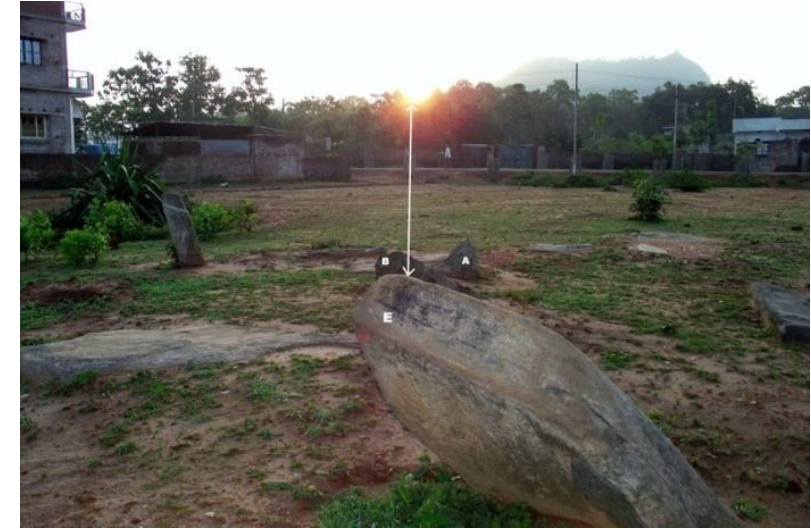

Plate 7. The same B \& E stones from the opposite side are aligned towards the Summer Solstice sunrise.

The smaller triangular pointer $\mathrm{B}$ along with $\mathrm{E}$ is aligned to the Winter Solstice sunset of 21/22 Dec (Pl 6) (Fig 1). From the opposite, the same E \& B stones are in faultless alignment with the sun rising from behind the left gradient of the Silwar Hill on Summer Solstice mornings of 20/21 Jun (Pl 7) (Fig 1). The smallest triangle $\mathrm{A}$ has been placed in such a manner that it unerringly points towards an unnamed hill from whose rear the sun rises in the mornings of the Winter Solstice of $22 / 23$ Dec. (Pl 8. The photograph being relatively new shows a house now obstructing the hill).

During the course of our study of the site, we discovered that the site's North-South axis was devised by intelligent positioning of the stones. The North-South axis touching the phallus $C$ is made to pass through the gap between the two triangles and intersecting with the East-

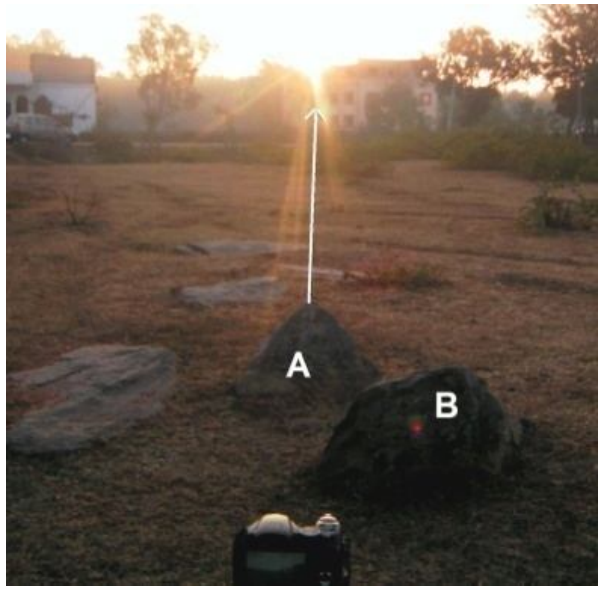

Plate 8 
West recumbent stone D it eventually unites with the "V" feature at the right flank of the Juljul Hill to the exact South of the megalith (Pl 9) (Fig 1). "V" cleaves across the world are known to be the symbol of the female vulva representative of the Mother Goddess (Das 2009).

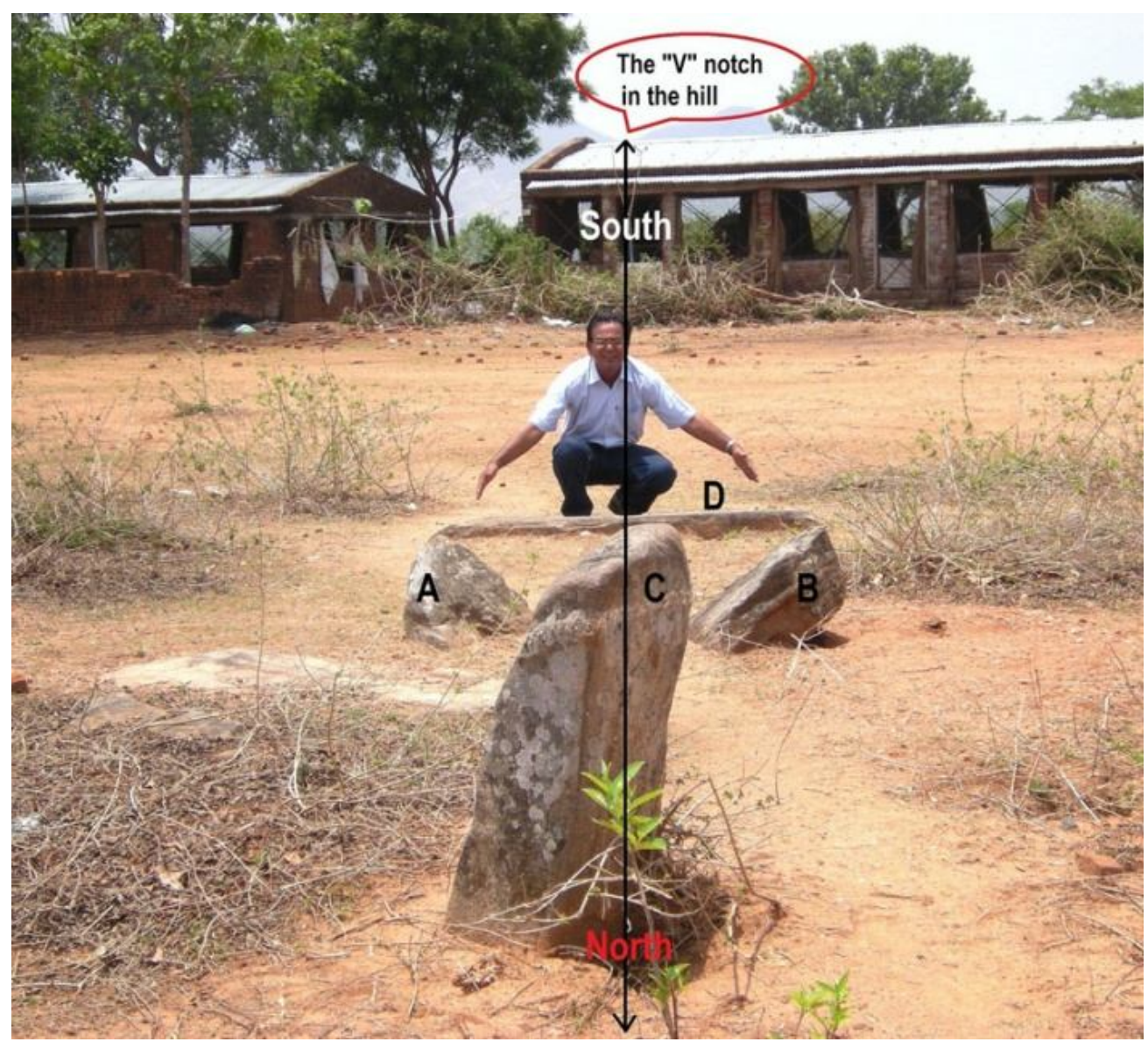

Plate 9. Photograph taken facing the South while standing on the North-South axis which finally passes through the "V" notch on the Juljul Hill. Photograph on the same axis also showing the arrangement

Sitting at a precise spot on the linear North-South axis of the monument and looking towards the Goddess Hill we perceived a remarkable image. We observed that both the opposite facing triangles A \& B had 'framed' the recumbent 'female' stone D from its either side. The phallus, very much a part of the model gracefully 'lifted' D in the middle ( $\mathrm{Pl}$ 9). One needs to bear in mind that it is at this female stone $\mathrm{D}$ the intercourse of both the North-South and East-West axis occurs. We marked the spot as $G$ from where this amazing image was witnessed, and we further discovered that a trifle drift from that point distorted the view!

This outstanding image of this model seems to be a symbolical illustration that can be conjectured as an allegorical union between the male phallus and the female stone; components of the now obsolete fecundity cult. Meaden believes that altered positioning of stones in a megalith was made in respect to the landscape for depiction of the sacred union (Meaden 1992). Judging by this one can understand that the prehistoric megalith makers had an in-detail planning for the creation of the shrine to also generate this amazing visual by sagacious alignments. 


\section{Measurement}

This dramatic image formulated by clever arrangement of the stones reveals the ancient megalith makers' brilliance. We decided to measure the distances between the stones to find out how they were able to create that image only to be viewed from a particular spot G. In the process, we observed that both the lengths between the point $\mathrm{F}$ amid the two smaller triangles and the decumbent stone $\mathrm{D}$ and $\mathrm{F}$ and the phallus $\mathrm{C}$ are equal. We were indeed more startled to see that the span between $G$, the point form where the said image could be viewed and $C$ is also similar to both the distances between $\mathrm{C}$ and $\mathrm{F}$ and $\mathrm{F}$ and $\mathrm{D}$ (Fig 1). Therefore the viewing of the striking illustration from $\mathrm{G}$ was a consequence of the equidistant placement of the stones.

We in the process learnt that to create such a spectacle, the ancient megalithic engineers not only had to possess reasonable knowledge and understanding of ratios as equals, halves, doubles, and apply them during the positioning of these stones but know the exact spot from where one could view the image of the sacred union (Fig 1). Chano therefore is evidence that the stones like in many other ancient megalithic complexes were not placed arbitrarily but with precise arrangement and measurement.

\section{Archaeological Appraisal}

The region is very significant archaeologically as this comprises of a large ancient cupule site and a few other prehistoric megalithic sites of different architectures. A dried river channel about 300 mtrs to the west of the site confirms that the once flowing river's banks may have had sustained human habitation. The field around the megalith is scattered with iron slags confirming smelting of iron in the past by tribes as Asur, Karmali or Lohra etc. The plough has extracted many iron implements as nail pairer, arrowhead and iron tattoo pin and even a dual serpent-head brass bangle (Pl 10) etc. We have also collected several broken shards of pottery of Black, Red, Painted Red, Black and Red and Black on Red et al from around the megalith and from a pit wall adjacent to it (Fig 11). A small relic that could be the fragment of a bone flute ( $\mathrm{Pl} \mathrm{12)}$ was yielded from the same trench.

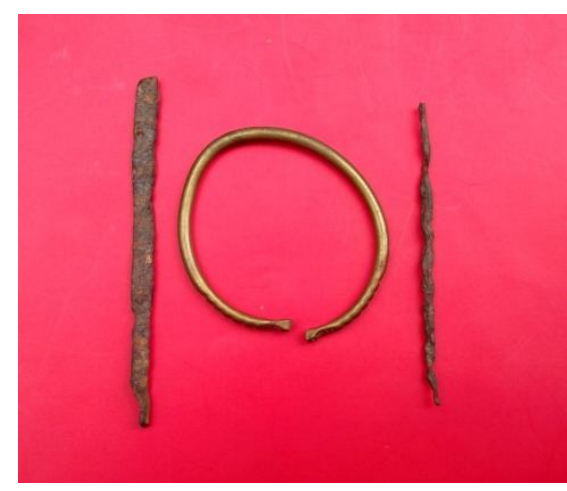

Plate 10. An iron nail pairer, one tattoo pin and one serpent head brass bangle. All collected from the field around the megalith.

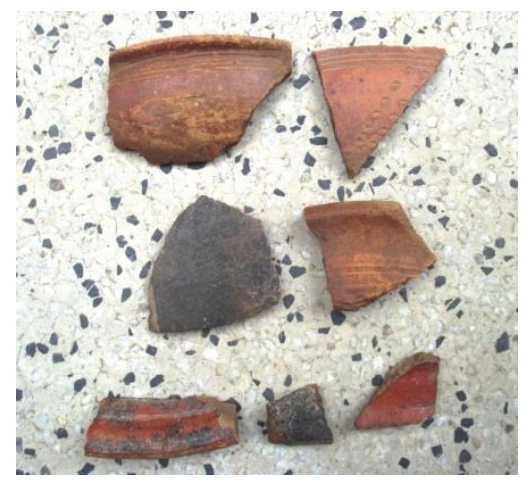

Plate 11. Potshards collected insitu from around the megalith

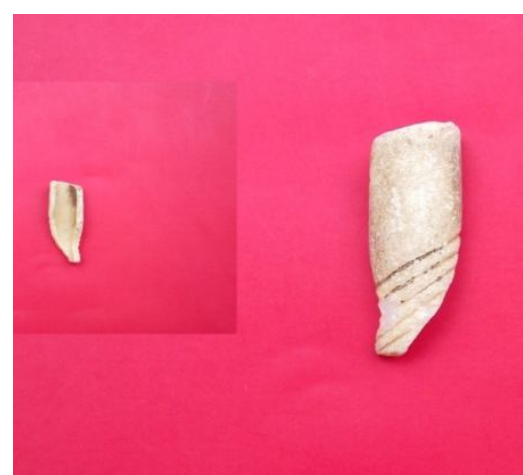

Plate 12. Fragment of a possible bone flute. Collected from a pit wall adjacent the megalith.

Excavation of the site is crucial to know about the type of burial inside the hargarhi, to learn about the builders of this amazing megalithic complex, study the grave yields and determine the date for the site. 


\section{Possible Purposes: Why was Chano built?}

Seeing the placement of the stones it could be rationally assumed that apart from functioning as a burial, the monument was also meant to serve some other purpose or purposes.

Plenty of the ancient menhirs in and around the districts of Hazaribagh and Ramgarh faces the Winter Solstice sunrise.

A bone burying ceremony of the megalithic Munda community of Jharkhand called jangtopa though dying is still prevalent in a few remote villages of the state. This ceremony though is held today in the month of magh in January but few still celebrate it around the winter solstice sunrise in December. In the ceremony, the deceased's bones are put in a pot and then inserted below an already existing sasandiri centre stone containing pots of the remains of the former dead family members. A new menhir may also be dug in upon the pot burial (Oraon 1964) facing the day's sunrise on which the bones are interred into the earth which could also be the day of Winter Solstice. Therefore the archaic Mundari jung-topa ceremony of burying bones of the dead on or around the Winter Solstice could be the possible reason behind the orientation of several menhirs towards the sunrise of this day. The reason behind Winter Solstice being so major for the ancient megalith makers as the Mundas is now forgotten by their current lot but it must have had something to do with fertility.

Observing the sunrises and sets of the Summer and the Winter Solstices by standing at the rear of the aligned stones perhaps enabled the custodian priest of the Chano megalith to know the dates of these sacred days to commence their fertility ceremonies. Therefore, apart from being a burial, Chano like many other astronomical megaliths was also an observatory of the sun for the ancient megalithic communities meant to function as their calendar.

The Chano megalith was once also a temple of the non-tribal cow herders who firmly believed that their "detas" (Gods) resided inside the burials. Several ancestor-worshipping rituals associated with megaliths are still in vogue among the dalits and the tribals of Jharkhand.

\section{Present Condition}

A megalithic temple-burial unlike temples or forts which can stand and thrive on their own, the landscape also forms its outer part. Each significant individual stone along with the site itself is aligned to the hills in the horizon therefore without such ancient alignments; a megalithic complex falls into disuse and becomes non-functional. Chano now lies threatened due to human proximity. With new buildings stemming all around, Chano's fascinating alignments to the hills is now thwarted; the astronomy of the site is lost forever. The stunning views of the Winter and the Summer Solstice sunrises and sets from the site, can no more be clearly viewed. The commoner having no understanding of these ancient sacred stones may tow them away for mundane domestic uses and such a noteworthy relic of prehistoric India will disappear forever in the process.

\section{Reference:}

1. Chakravarty, A.K. 2001. The Surya Siddhanta. The Asiatic Society. Kolkata.

2. Chakravorty, P.B. Monolith memorials of Meghalaya. Mar- Aug 93. Himalaya Today. 
3. Cope, J. 1998. The Modern Antiquarian. Thorsons. London. UK.

4. Cousens, H. 1926. The Chalukyan Architecture. Calcutta. Government of India.

5. Das, S. 2008. Some salient features of the surface architecture of megaliths of Hazaribagh. Purattatva. Number 38. New Delhi.

6. Das, S. 2009. Sacred Stones in Indian Civilization. Kaveri Books. New Delhi.

7. Das, S. 2010. Megaliths of Jharkhand : a new insight. ABACUS. Spring 2010. Vol 5.No 1. Journal of Architecture, Conservation and urban Studies. BIT. Messra.

8. Das, S. 2014. Unknown Civilization of Prehistoric India. Kaveri Books. New Delhi.

9. Earls, I. 2011. Sky and Landscape. Fastprint Publishing. Peterborough. England.

10. Hutton, J.H. 1922. The meaning and Method of the erection of Monoliths by the Naga Tribes. The Journal of the Royal Anthropological Institute of Great Britain and Ireland. Vol II.

11. Kosambi, D.D 1962. Myth and Reality Studies in Indian Culture. Popular Prakashan. Mumbai.

12. Meaden, T. 1992. Stonehenge.The Secret of the Solstice. Souvenir Press. Great Britain.

13. Meaden, T. 1999. The Secrets of the Avebury Stones. Souvenir Press. Great Britain.

14. Oraon, P.C. 1964. Life and Times of Birsa Bhagwan. Bihar Tribal Research Institute. Ranchi.

15. Rao, N.K \& Thakur, P. 2010. The astronomical significance of megalithic stone alignments at Vibhuthihalli in Northern Karnataka. Journal of Astronomical History and Heritage.

16. Rao, N.K, Thakur. P \& Mallinthpur, Y. 2011. Astronomical Significance of Nilurallu the Megalithic Stone Alignment at Murardoddi in Andhra Pradesh. Journal of Astronomical History and Heritage.

Subhashis Das is an Individual Researcher and author on Megaliths of Jharkhand and India. He has been exploring and researching on various megalithic sites discovered by him, for the last 20 years. The author has authored many papers on national and international journals. He lectures all over the country and abroad on his discoveries on megaliths. He has discovered the Equinox viewing facet in the PUNKRI BURWADIH megaliths placing it in the same pedestal with several other European megaliths. Today hundreds gather twice a year in the megalithic site to view the spectacle of the Equinox sunrise making Punkri Burwadih the only megalithic site in the country to view such a phenomenon. He has authored two books on his discovery and research: a). SACRED STONES IN INDIAN CIVILIZATION. b). UNKNOWN CIVILIZATION OF PREHISTORIC INDIA. His forthcoming book THE ARCHAEOASTROMY OF A FEW MEGALITHIC TEMPLES OF JHARKHAND is slated to be released by the end of this year. He was invited to speak on megaliths in the $14{ }^{\text {TH }}$ WORLD CONFERENCE of PREHISTORY at Burgos University in Spain. He has also presented a paper in the $8^{\mathrm{TH}}$ WORLD ARCHAEOLOGICAL CONGREES (WAC) IN KYOTO, JAPAN. His website on Megaliths of India is the only website on Megalith in India. Several documentaries on the megalithic sites he has discovered and the ones which are his study sites have been aired on channels as National Geographic and Doordarshan etc. 